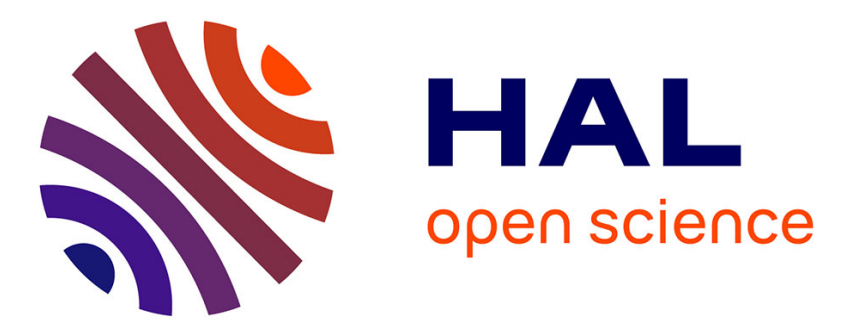

\title{
The Observation of the Martensite-Like Shear Diffusionless $\alpha \rightarrow \gamma$ Transformation in Carbon Steels with Pearlitic Structure
}

\author{
V. Schastlivtsev, I. Yakovleva, T. Tabatchikova, D. Mirzaev
}

\section{To cite this version:}

V. Schastlivtsev, I. Yakovleva, T. Tabatchikova, D. Mirzaev. The Observation of the MartensiteLike Shear Diffusionless $\alpha \rightarrow \gamma$ Transformation in Carbon Steels with Pearlitic Structure. Journal de Physique IV Proceedings, 1995, 05 (C8), pp.C8-531-C8-536. 10.1051/jp4:1995882 . jpa-00254131

HAL Id: jpa-00254131

https://hal.science/jpa-00254131

Submitted on 1 Jan 1995

HAL is a multi-disciplinary open access archive for the deposit and dissemination of scientific research documents, whether they are published or not. The documents may come from teaching and research institutions in France or abroad, or from public or private research centers.
L'archive ouverte pluridisciplinaire HAL, est destinée au dépôt et à la diffusion de documents scientifiques de niveau recherche, publiés ou non, émanant des établissements d'enseignement et de recherche français ou étrangers, des laboratoires publics ou privés. 


\title{
The Observation of the Martensite-Like Shear Diffusionless $\alpha \rightarrow \gamma$ Transformation in Carbon Steels with Pearlitic Structure
}

\author{
V.M. Schastlivtsev, I.L. Yakovleva, T.I. Tabatchikova and D.A. Mirzaev* \\ Institute of Metal Physics, Ural Division of Russian Academy of Sciences, Ekaterinburg, Russia \\ * Chelyabinsk' State Polytechnical University, Chelyabinsk, Russia
}

\begin{abstract}
The structure of eutectoid carbon steel with the initially pearlitic structure was studied by transmission electron microscopy and electron diffraction after laser heating. It is shown that, under ultrarapid laser heating, the $\alpha-\gamma$ phase transformation can proceed by a shear-type diffusionless mechanism that results in the deformation of cementite platelets. The crystallographic characteristics of shear planes involved in the $\alpha-\gamma$ transformation are determined. Austenite formation was found to occur through the diffusionless shear mechanism, with orientation relationships close to those of Kurdjumov-Sachs.
\end{abstract}

\section{INTRODUCTION}

The classic theory of phase transformations treats the process of austenite formation from a ferritic-cementitic matrix upon heating as a typical random diffusional phase transformation. Austenite nucleation is proceeded by composition fluctuations which are most likely to occur at the ferrite/cementite phase boundaries or at the ferrite grain (subgrain) boundaries. Long ago, V.D. Sadovskii called attention to the fact that the mechanism of austenite formation may change, depending on the heating rate, much in the same manner as the austenite decomposition mechanism (random diffusion, intermediate, or diffusionless shear) depends on the cooling rate.

The purpose of this work is to experimentally study the austenite formation mechanism in the steels with a starting pearlitic structure upon ultrarapid laser heating, and to find out whether a diffusionless "crystallographically ordered" phase transformation in steels is possible upon heating.

\section{EXPERIMENTAL}

The samples of U8 eutectoid steel $(0.82 \% \mathrm{C})$ had a fully pearlitic structure. The interlamellar spacing in the pearlite was $0.45-0.5 \mathrm{~mm}$. An LT 1-2 type laser was used for heating. The rate of the laser heating was $10^{3}-10^{4} \mathrm{~K} / \mathrm{s}$. The radiation power was $1 \mathrm{~kW}$. The velocity of the sample movement under the laser beam was $1 \mathrm{~m} / \mathrm{min}$. Optical and electron microscopes were used to study the structure. Foils for the analysis were prepared from sections cut parallel and perpendicular to the sample surface. This enabled us to examine the structure in regions that were heated to different temperatures, and, thus, to follow the austenitization process in detail. Local laser heating allows one to study structure changes occurring in heating through the critical range. 


\section{EXPERIMENTAL RESULTS}

As the heating temperature rises above $A c_{1}$, the $\alpha \rightarrow \gamma$ transformation starts, which can be detected by structure changes inside the pearlite colonies. Let us first consider the shape of the transformed regions. Figure 1a shows a fragment of a pearlite colony in the U8 steel after laser heating where only one of the ferrite lamellae underwent $\alpha \rightarrow \gamma$ transformation, whereas the neighboring plates remained untransformed. The formed austenite transformed into martensite during subsequent cooling. Therefore, Fig. 1a displays a martensitic structure which developed in the site of a ferrite lamella and is confined between two undissolved cementite lamellae. It is worth noting that the $\alpha \rightarrow \gamma$ transformation occurred in an extremely small localized volume (only one ferrite lamella), which suggests the shear transformation mechanism rather than the fluctuation one.

Moving along the transformed lamella, we could estimate the character of the $\alpha \rightarrow \gamma$ transformation front movement (i.e., the $\alpha / \gamma$ interface). The front moved along the ferrite lamellae extremely nonuniformly: in the adjacent ferrite lamella, it lagged behind that in the transformed lamella by several micrometers.

The nonuniform character of the $\alpha \rightarrow \gamma$ transformation front movement inside a separate ferrite lamella is more evident in Fig. 1b. The $\alpha \rightarrow \gamma$ transformation front has the shape of a sharp protuberance (with the vertex angle of about $40^{\circ}$ ). The maximum rate of the austenite advance is observed along the central axis of the ferrite lamella rather than near its edges in the vicinity of the cementite lamellae. This fact is difficult to explain in terms of the hypothesis that the $\alpha \rightarrow \gamma$ transformation proceeds by the diffusion mechanism, in which case fluctuations in the ferrite composition toward greater carbon content would facilitate the transformation. However, the observation is in accordance with the diffusionless mechanism of the transformation. An analysis of dark-field electron micrographs shows that, upon cooling, the fresh austenite transforms into ferrite rather than into martensite because the structure transformed is homogeneous.

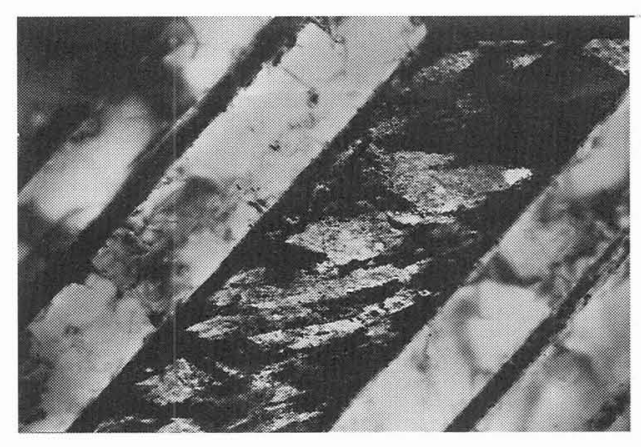

a

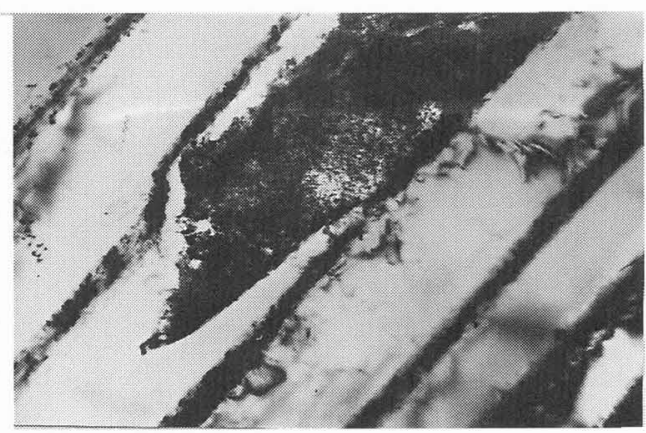

b

Fig. 1. Formation of austenite inside a pearlite colony and front of the $\alpha \rightarrow \gamma$ transformation upon laser heating of eutectoid steel. (a), (b) - the different stages of the transformation.

The results of the microstructure investigations suggest that under the heating conditions 
used in our study, the austenite is formed inside the pearlite colonies through the shear mechanism. In this case, certain orientation relationships (OR) must exist between the austenite and the starting ferrite. In order to establish them, the crystallografic orientations of the steel structura components were determined using transmission electron microscopy. These orientation relationships cannot be determined directly, because during cooling austenite transforms into martensite. The orientation relationships between austenite and martensite for the shear transformations upon cooling are known. These are either the Kurdjumov-Sachs OR or intermediate orientation relationships that differ from the former by 2 to $3^{\circ}$. The indirect method consists in reconstructing the austenite orientation from which martensite was formed, on the basis of the above orientation relationships.

From an electron diffraction pattern, two variants of martensite orientation with the $(221)_{\alpha}$ (orientation M1) and (533) $\alpha$ (orientation M2) zone axes were determined. The austenite orientation, constructed on the basis of these data, is shown in Fig. 2a. In order to check the construction, one more martensite orientation (M3) was determined, with the zone axis close to $(331)_{\alpha}$. This orientation was in the same transformed ferrite lamella, but in a different place. Orientation M3 was compared with the austenite orientation (orientation M3 is not shown in Fig. 2 a to find that it was close to the Kurdjumov-Sachs $O R$. This proves the construction of the austenite orientation to be correct.

Now the mutual orientation of the pearlitic ferrite and austenite formed from it can be determined. Figure $2 \mathrm{~b}$ shows the pole figures for ferrite $(\mathrm{F})$ and austenite $(\mathrm{A})$. The orientation relationships between these phases are seen to be close to the Kurdjumov-Sachs OR, which indicates the oriented character of the austenite formation.
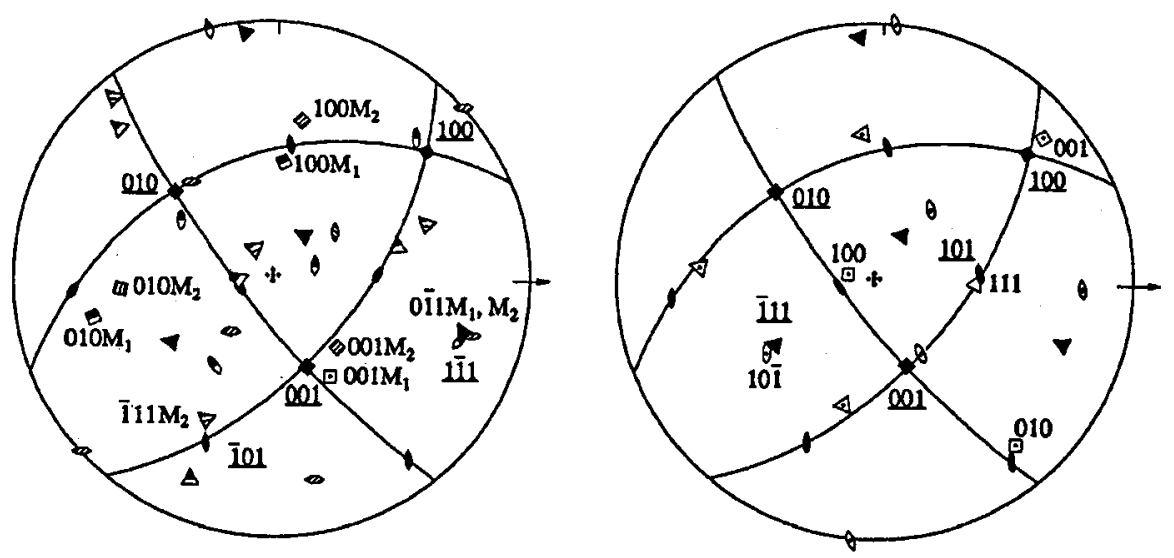

Fig. 2. Pole figures indicating orientations of the initial ferrite $F$ (light signs), final orientations of martensite $M_{1}$ and $M_{2}$ and the reconstructed orientation of austenite $A$ (dark signs).

As the heating temperature increases further, i.e., as the irradiated surface is approached, the pearlitic ferrite fully transforms into austenite. Under these conditions, cementite starts to dissolve rapidly. In the zone of full quenching, a martensitic structure is observed after cooling, without any traces of cementite lamellae in it. 


\section{DISCUSSION}

There are three general features of a martensite-like transformation. First, it must be diffusionless. Second, it must proceed by the shear type rebuilding of the crystal structure, which, in most cases, leads to lamellar products of the transformation. And third, the parent and final phases should have an orientational relationship.

Let us consider the structure of the U8 steel in the zone where the $\alpha \rightarrow \gamma$ transformation begins. Some cementite lamellae are seen to acquire a complicated defective structure because they are heated to a temperature slightly above $A c_{1}$. Defects of a few types are seen to be regularly arranged. Small defects, which are visible only in the negatives, formed a network with a cell of $10 \mathrm{~nm}$ in size. A coarser defect system shows a period of $150 \mathrm{~nm}$. The defects, parallel to the habit plane, are associated with variations in the cementite structure and will be analyzed in our next paper. Defects of still another type exist; they intersect cementite plates at an angle of about $60^{\circ}$. The orientation relationships between the ferrite and cementite were found to be of the Bagaryatskii or, to be more exact, of the Isaichev type: $(103)_{c} \|(110)_{f}$.

We consider the scheme of the structure of a cementite plate (Fig.3) The defects arranged parallel to the plate surlface are likely to belong only to cementite, whereas the defects crossing the plate extend into ferrite. It was of interest to identify the plane in which the defects lie. Dark-field image of the plate shows that it has two surfaces. One of them is the section of the cementite plate by the plane of the foil; the section is close to the $(311) \mathrm{c}$ plane. The other image is the projection of the habit plane of the cementite plane. In a pearlite structure that obeys the Bagaryatskii's type of orientation relationship, the habit plane $(101)_{c}$ of a cementite plate is known to coincide with the $\{211\}_{\mathrm{f}}$ planes. Both of the above-mentioned cementite surfaces exhibited shear lines; this makes it possible to use a two-trace analysis and to index the shear planes in the ferrite and cementite as $(110)_{\mathrm{f}} \|(103)_{\mathrm{c}}$ (Fig. 3).

One might associate the observed shear with the beginning of the heat-induced formation of austenite by shear mechanism. With a further increase temperature, the structure evolution of the same pearlite colony can be observed. Here, the cementite platelets look appreciably modified: steps of a special kind form in them and, finally, the platelets break down; their fragments move relative one another out of the original position. Yet, the shear plane remains unchanged, despite the broadening of the slip band. Within the slip band, individual parts of the platelet shift from the original locations but do not dissolve in austenite because ferritic structure formed on cooling in the slip band area. Dislocations that appear in this area are likely to be due to the binary $\alpha \rightarrow \gamma$ transformation.

The interaction between austenite and cementite may be the causes of the deformation of the latter. We analyzed the situation, and found that at the Bagaryatskii OR, when the habit plane of the cementite platelet is parallel to $(101)_{\mathbf{c}} \|(211)_{\mathbf{f}}$, four alternatives are possible for the platelet habit plane which is intersected by the $\{110\}_{\mathrm{f}}$ planes of ferrite in which the shear proceeds through three different slip directions of the (111)f type. The habit and the shear planes may meet at the angles $90.0^{\circ}, 73.22^{\circ}, 54.74^{\circ}$, and $30.0^{\circ}$. The scheme of the formation of 
austenite nuclei for different angles of the intersection of the planes is given in Fig. 4.

The above results indicate that, under rapid laser heating, austenite can form through a diffusionless shear-type martensite-like mechanism. The $\alpha-\gamma$ transformation develops, in this case, in the ferritic matrix of the steel, regardless of whether a carbide phase does or does not exist. Yet, it does not mean that the carbide phase is not affected. On the contrary, the formation of austenite may cause structure modifications in the cementite located in the immediate vicinity of the austenite.

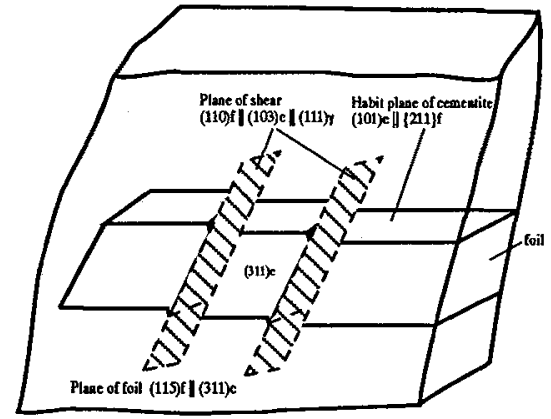

Fig. 3. Determination of the shear plane involved in the $\alpha \rightarrow \gamma$ transformation: the picture of the section plane of a cementite platelet by the foil plane (schematic).
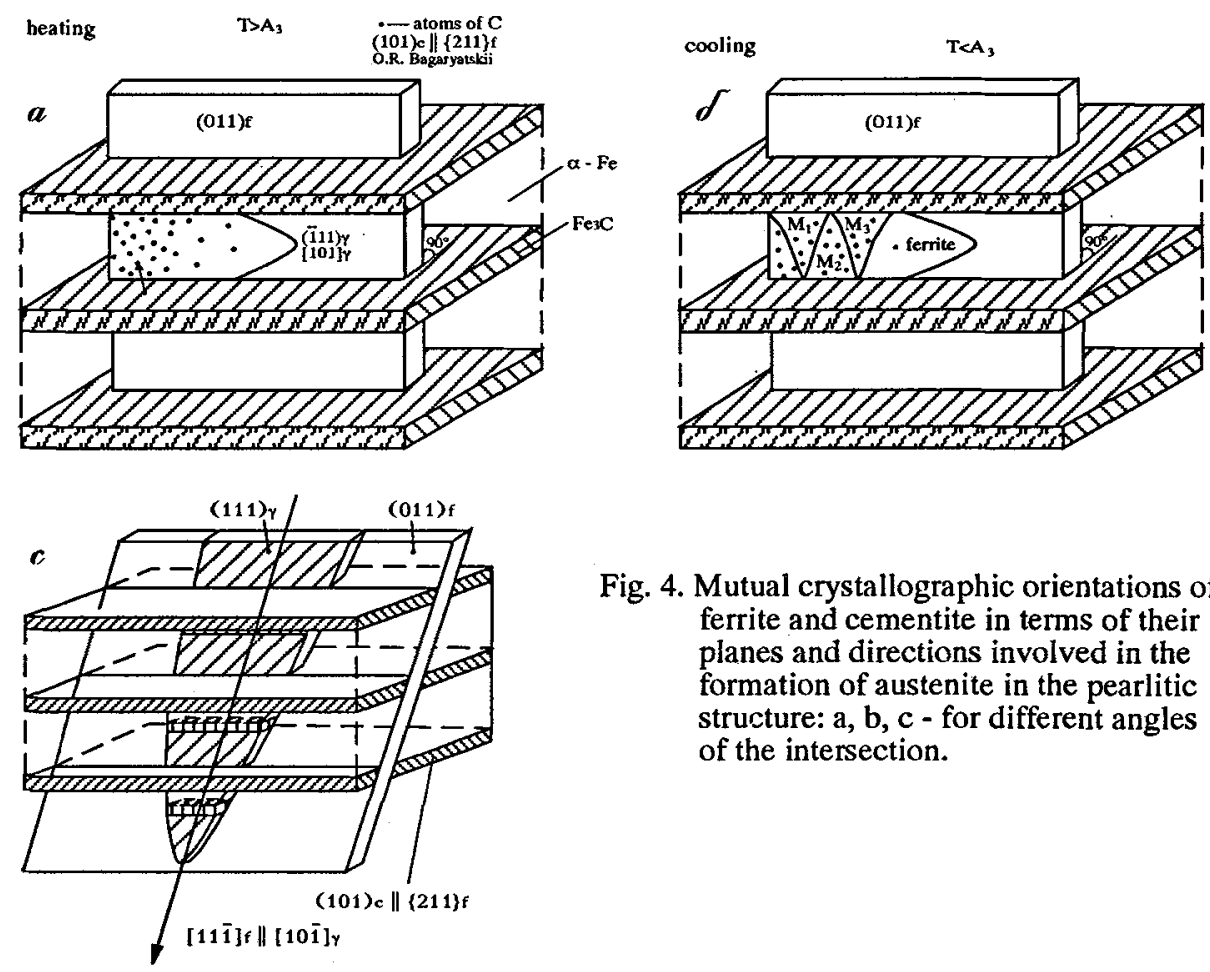

Fig. 4. Mutual crystallographic orientations of ferrite and cementite in terms of their planes and directions involved in the formation of austenite in the pearlitic structure: $a, b, c$ - for different angles of the intersection.

In austenite formed by the diffusionless mechanism, the carbon content cannot exceed the solubility limit in ferrite, i.e., $0.02 \%$. Therefore, the austenite will start, after the shortest holding, to absorb carbon by dissolving carbides; the phenomenon can be observed by 
experiments and may lead to the wrong conclusion that diffusion is involved in the transformation process.

\section{CONCLUSION}

Based on the electron-microscopy data obtained here, we can make the following conclusions.

Under rapid laser heating, austenite can nucleate in a pearlitic structure of steels by a shear-type diffusionless martensite-like mechanism; in doing so, OR of the Kurdjumov-Sachs type are detected between the original ferrite (or the ferrite component of the pearlite structure) and the austenite formed. This austenite plate may be considered as real $\gamma$-martensite. The transformation occurs only in the ferrite, i.e., in a single-phase system. The involvement of a carbide phase is not required. However, when existing, it can influence the transformation, e.g., in terms of the selection of the shear planes in the ferrite.

The as-formed austenite contains little carbon. Therefore, carbides immediately begin to dissolve in it. This dissolution results in an increase in the carbon content in the austenite and, hence, obscures the true transformation mechanism.

It appears that maximal heating rates are needed to ensure the shear-type diffusionless $\alpha-\gamma$ transformation in pearlite. These rates cannot always be achieved, even under laser heating. At slower heating rates, the formation of austenite can also occur through a diffusionless, but massive, transformation; the latter differs from the shear-type transformation in the migration behavior of iron atoms.

\section{REFERENCES}

[1]. I.L. Yakovleva, V.M. Schastlivtsev, and T.I. Tabatchikova. Experimental Observation of Diffusionless Formation of Austenite in a Steel with Pearlitic Structure upon Laser Heating, Fiz. Met. Metalloved., 1993, vol. 76, no. 2, pp. 179 - 187.

[2]. I.L. Yakovleva, V.M. Schastlivtsev, T.I. Tabatchikova, D.A. Mirzaev, and A.L. Osintseva. A Diffusionless Shear-Type Martensite-like Mechanism of the Formation of Austenite in a Pearlitic Steel During Laser Heating, Fiz. Met. Metalloved., 1995, vol. 79, no. 5, pp. 576 580. 